\title{
UMA ANÁLISE DA POLÍTICA DO RECONHECIMENTO NAS RELAÇÕES CONJUGAIS PELA LITERATURA DE JANE AUSTEN
}

\author{
AN ANALYSIS OF THE RECOGNITION POLICY IN MARITAL RELATIONS BY THE \\ LITERATURE OF JANE AUSTEN
}

\author{
Pedro Henrique Nascimento Zanon \\ Doutor e Mestre em Direito \\ Faculdade de Direito de Vitória (FDV) \\ Vitória - ES. Brasil \\ phzanon@gmail.com
}

Resumo: Este artigo tem como objetivo a análise das relações conjugais atrelada à matriz teórica da política de reconhecimento. Com inspirações no romance de Jane Austen, Orgulho e preconceito $(O \& P)$, a problemática neste trabalho gira em torno de como as políticas de igualdade de gênero nas relações conjugais são moldadas no século XXI. O movimento feminista e a luta por igualdade de gênero ganharam espaço na agenda política internacional do século XX e XXI, porém, a despeito dos avanços alcançados, a desigualdade de gênero ainda possui severas disparidades no cenário político e jurídico. O objetivo é analisar a igualdade de gênero pela política do reconhecimento de Charles Taylor enquanto base teórica associando-a aos apontamentos de Austen. Trata-se de um trabalho jurídico de aporte literário e sociológico, com utilização do instrumental teórico e metodológico da Literatura justaposta com o Direito. Propomos então uma metódica do surrealismo jurídico da epistemologia carnavalizada do Direito, defendida por Luis Alberto Warat. A análise de $O \& P$ pela interdisciplinaridade entre a Literatura e o Direito promove um aprofundamento de reflexões sobre nossas instituições jurídicas.

Palavras-chave: Feminismo. Igualdade de gênero. Jane Austen. Orgulho e preconceito.

Abstract: This article aims to analyze the conjugal relations linked to the theoretical matrix of recognition policies. Inspired by Jane Austen's novel Pride and Prejudice $(P \& P)$, the problem in this work revolves around how gender equality policies in marital relationships are shaped in the $21 \mathrm{st}$ century. The feminist movement and the struggle for gender equality have gained ground on the international political agenda of the 20th and 21 st century, but despite the advances made, gender inequality still has severe disparities in the political and legal landscape. The objective is to analyze gender equality by the policy of Charles Taylor's recognition as a theoretical basis associating it with Austen's notes. It is a legal work of literary and sociological contribution, using the theoretical and methodological tools of Literature juxtaposed with the Law. We then propose a method of the legal surrealism of the carnivalized epistemology of Law, defended by Luis Alberto Warat.

Keywords: Feminism. Gender equality. Politics of Recognition. Jane Austen. Pride and Prejudice.

\section{Para citar este artigo}

ABNT NBR 6023:2018

ZANON, Pedro Henrique Nascimento. Uma análise da política do reconhecimento nas relações conjugais pela literatura de Jane Austen. Prisma Jurídico, São Paulo, v. 19, n. 2, p. 245-265, jul./dez. 2020. http://doi.org/10.5585/prismaj.v19n2.17361. 


\section{Introdução}

A partir da contextualização da narrativa da literatura de Jane Austen, intitulada Orgulho e Preconceito (1982) ( $O \& P$ ) o objetivo neste artigo é demonstrar o impacto da política do reconhecimento nas relações conjugais por uma abordagem que relaciona os assuntos jurídicos e sociais com a crítica literária. Austen, através do romance que envolve os personagens $\mathrm{Mr}$. Darcy e Elisabeth, instiga um debate sobre a abstração amorosa e a contenção da identidade feminina pela imperiosa necessidade de casar-se para manter o status social em uma sociedade de classes e os negócios da família. Da mesma forma Mr. Darcy não pode ser considerado senhor das suas ações, pois assim como Elisabeth somente será uma pessoa honrada ao vincular-se em casamento. Essa singela condensação de ideias pode ser ilustrada logo na primeira passagem da literatura:

\footnotetext{
É uma verdade universalmente conhecida que um homem solteiro, possuidor de uma boa fortuna, deve estar necessitado de esposa. Por pouco que os sentimentos ou as opiniões de tal homem sejam conhecidos ao se fixar numa nova localidade, essa verdade se encontra de tal modo impressa nos espíritos das famílias vizinhas que o rapaz é desde logo considerado a propriedade legítima de uma das suas filhas. (Austen, 1982, p. 9) (grifo nosso).
}

É nesse caminhar cognitivo de ideias que se situa este ensaio teórico: conhecer nossa formação enquanto coletividade contribui para a tomada de decisões mais assertivas sobre as circunstâncias sociais que vivemos. Para isso, utilizamos a regência do instrumental teórico e metodológico da Literatura justaposta com o Direito. A pesquisa entre essas duas grandes áreas do pensamento parece tarefa complexa e delicada. Por isso, acompanharemos o pensamento de Luis Alberto Warat, que "inaugurou, no Brasil, esse movimento extremamente fecundo de diálogos e aproximações da literatura com os textos jurídicos" (Pepe, 2016, p. 7). Propomos então uma metódica do surrealismo jurídico da epistemologia carnavalizada do Direito, defendida por Warat (1985), no entendimento de que ela contribui para um melhor conhecimento de nossas circunstâncias sociais. Nos lembramos do pensamento de José Ortega y Gasset (1987, p. 52): "Eu sou eu e minha circunstância, e se não salvo a ela, não me salvo a mim". Nesse sentido, uma "compreensão carnavalizada do mundo, reintroduziria o valor das ilusões e metáforas banidas pela hiper-realidade da pós modernidade".

Passamos assim a considerar que o enredo crítico contido na obra se torna objeto de debate de questões sociológicas que permeiam nossas instituições jurídicas. Além do marco literário de Jane Austen, utilizamos a matriz teórica de Charles Taylor para analisar a igualdade de gênero pela ótica da política do reconhecimento. Nesse sentido, diz Antonio Candido (2017, 
p. 177) que "nas nossas sociedades a literatura tem sido um instrumento poderoso da instrução e educação, entrando nos currículos, sendo proposta a cada um como equipamento intelectual e afetivo".

Orgulho e preconceito relata o drama de mulheres do século XVIII que, impossibilitadas de regerem suas vidas em termos materiais e sociais, eram alvo de casamentos arranjados por interesses de suas famílias e de uma sociedade com marcas do patriarcado. A crítica de Austen ataca a formação da sociedade compostas por hierarquias sociais que adotava uma imagem depreciativa das mulheres. O contexto do romance situa a transição do ideal de casamentos arranjados por interesses familiares na hierarquia social, para casamentos como produto do amor romântico entre os nubentes construídos por uma moral religiosa.

Este artigo parte da análise sobre os relatos literários de uma relação conjugal instrumental e que retrata o fenômeno que chamamos de mercantilização dos casamentos no século XVII e XVIII. A supressão da liberdade de manifestação de vontade feminina é um marco nesta literatura analisada, pois revela os grilhões da realização de seu matrimônio pela vontade e anuência de seu pai que decidia conforme as necessidades financeiras da família. Formulamos, assim, a intrínseca relação entre a teoria política do reconhecimento em Charles Taylor com as implicações do matrimônio e as noções de honra e dignidade como princípios da sociedade patriarcal.

$\mathrm{Na}$ toada dessa análise, retratamos o problema que assola tanto a Elizabeth quanto a Mr. Darcy sobre a imposição do matrimonio. A figura da comunhão aparece de forma opressora a ambos, mas recai em Elizabeth de forma ainda mais drástica, pois a estrutura patriarcal da época reprimia seus desejos e direito de manifestar vontade. Essa análise retrata a identidade individualizada dando ênfase ao self feminino e ao caráter dialógico na relação com o outro.

Por fim, o desfecho deste artigo se manifesta pela construção da crítica a uma cultura estática e anestesiada da igualdade de gênero. O movimento feminista e a luta por igualdade de gênero ganharam espaço na agenda política internacional do século XX e XXI, porém, a despeito dos avanços alcançados, a desigualdade de gênero ainda possui severas disparidades. A problemática neste trabalho gira em torno de como as políticas de igualdade de gênero nas relações conjugais são moldadas no século XXI. Trata-se, portanto, de um trabalho jurídico de aporte literário e sociológico com objetivo de debater a igualdade de gênero pela política do reconhecimento de Charles Taylor. O autor possui influência declarada na filosofia Hegel, em especial na Fenomenologia do Espírito. Jane Austen foi contemporânea de Hegel e é 
considerada como a tradução do pensamento hegeliano na literatura, apesar de seus escritos não terem influência hegeliana, por impossibilidade cronológica ${ }^{1}$.

\section{Relatos de uma relação instrumental contidos na narrativa da obra Orgulho $e$ preconceito de Jane Austen}

"- Como se chama ele?

- Bingley.

- É casado ou solteiro?

- Oh, solteiro, naturalmente, meu caro. Solteiro e muito rico! Quatro

ou cinco mil libras por ano. Que boa coisa para as nossas meninas, hem?

- Como assim? De que modo pode isso afetá-las?

- Meu caro Mr. Bennet - replicou a esposa -, como você, às vezes, é enfadonho! Deve saber que ando pensando em casar uma delas..." (Austen, 1982, p. 89).

A epígrafe deste capítulo ilustra o contexto da literatura de Jane Austen com a fonte imaginária da sociedade falocêntrica e hierarquizada do século XVIII. Esta literatura demonstra como a identidade feminina vincula-se por um roteiro social que reproduz impacto no âmbito jurídico. Desta forma, nasce uma relação entre o Direito e a Literatura. De acordo com Trindade e Bernsts (2017, p. 8): “ [...] a literatura sempre foi uma das principais rotas de fuga para a construção de um pensamento crítico por meio da transdisciplinaridade". Ainda, segundo Trindade (2016, p. 01):

\footnotetext{
Repensar o direito, neste início de século, é o desafio que se impõe aos juristas. E, dentre as inúmeras e mais variadas alternativas que se apresentam na atualidade, o estudo do direito e literatura assume especial relevância. Além do destaque que confere à interdisciplinaridade, na medida em que se baseia no cruzamento dos caminhos do direito com as demais áreas do conhecimento - fundando um espaço crítico por excelência, através do qual seja possível questionar seus pressupostos, seus fundamentos, sua legitimidade, seu funcionamento, sua efetividade, etc. -, a possibilidade da aproximação dos campos jurídico e literário permite que os juristas assimilem a capacidade criadora, crítica e inovadora da literatura e, assim, possam superar as barreiras colocadas pelo sentido comum teórico, reconhecendo a importância do caráter constitutivo da linguagem no interior dos paradigmas da intersubjetividade e intertextualidade.
}

Jane Auste $(O \& P)$ induz reflexão sobre a opressão às mulheres pelo estilhaçamento da identidade feminina que deve ser pensado ainda hoje de forma crítica para questionar imposições sociais dadas como naturalizadas. Essas problematizações enfrentam as barreiras 
colocadas em um "sentido comum teórico", como ressalta o Trindade, e fomenta a criação de novas perspectivas sobre o tema.

O romance $O \& P$ foi publicado em 1813, mas acabado anos antes ${ }^{2}$, satiriza o casamento por interesse de famílias de classes e reflete o drama da impotência das mulheres no cenário social. A obra situa-se na era georgiana do Reino Unido, onde o casamento compreendia "os momentos mais importantes no ciclo de vida [do indivíduo]" só comparável à vida e à morte (Gillis, 1985, p.6). Pela legislação da época ${ }^{3}$, marido e esposa formavam uma única pessoa de direito, pois a existência legal da mulher incorporava-se na do marido, a começar pela retificação do sobrenome com retirada do sobrenome original, considerado como nome de solteira (Blackstone, 1915, p. 442). Sob esse contexto, o romance retrata o drama de uma família preocupada com a existência de cinco filhas solteiras e com a possíbilidade de com a morte do patriarca, os bens serem herdados a um parente distante.

Infelizmente para as suas filhas, esta propriedade estava legada a um parente distante, pois não havia herdeiros masculinos diretos; e a fortuna da mãe, embora suficiente para a sua situação na vida, mal bastava para suprir as deficiências da fortuna do pai (Austen, 1982, p. 32).

As mulheres, quando diante de um pretendente de boa hierarquia, não tinham discricionariedade de manifestar sua vontade sobre a escolha de seus parceiros ou se desejavam o casamento. Sufocava-se suas vontades em decorrência da posição na classe social. No mesmo sentido, um homem solteiro, possuidor de uma boa fortuna, deveria estar necessitado de esposa para situar-se na sociedade hierarquizada. Não importava se havia afetividade entre o casal, importava não estar solteiro. O casamento formava a honra e o orgulho da família.

A noção de honra foi influente no medievo e no feudalismo e se sustentou até o início da era moderna nas sociedades hierarquizadas. Honra representa status, fonte de solidariedade entre socialmente iguais e linha de demarcação contra socialmente inferiores (Berger, 1983, p. 174). A estrutura social monárquica espelhava o conceito de honra aduzido por Montesquieu $(2000)^{4}$ com a indispensabilidade de existirem preferências e distinções entre as hierarquias sociais. Atribuir sistemas de preferência e distinções significa destinar a cada indivíduo o que lhe é devido por referência à respectiva classe hierárquica. Obrigações de honra divergem entre

\footnotetext{
${ }^{2}$ O prelo de O\&P foi submetido para publicação em 1796 e 1797 por Jane Austen com o título de First Impressions, mas a primeira apresentação à editora de Thomas Cadell não obteve sucesso e o manuscrito foi rejeitado. O\&P apenas convenceu os editoriais para publicação em 1813 , após o sucesso de Razão e Sensibilidade, publicado em 1811 (Austen, 1982, p. 3).

${ }^{3}$ As duas leis mais significativas foram a Lei do Casamento de 1753 (Lord Hardwicke's Marriage Act of 1753) e da Lei de Casamentos Reais de 1772 (Royal Marriages Act of 1772). Como fonte histórica, foi utilizada a obra Commentaries on the Laws of England do jurista britânico William Blackstone em que faz comentários às leis vigentes até 1769 (Blackstone, 1915, p. 38).

${ }^{4}$ CAPÍTULO VII da obra Do princípio da monarquia. O governo monárquico supõe, como dissemos, preeminências, hierarquia e até uma nobreza de origem. A natureza da honra é requerer preferências e distinções; está, pois, por essência, colocada neste governo. (Montesquieu, 2000 , p. 45)
} 
as diferentes categorias de indivíduos, especialmente entre homens e mulheres ${ }^{5}$, pela ideia de preferências e distinções.

No século XVIII, Rousseau (2006, p. 33) critica a ideia da honra ao atrelá-la à formação de atos de vaidade, desprezo por uma classe superior, vergonha e inveja em classe inferiorizada por ir de encontro à felicidade e à inocência. A honra se constitui pela opinião alheia o que torna os indivíduos dependentes uns dos outros, de acordo com Taylor:

Você depende dos outros não simplesmente porque eles detêm poder político, ou porque você precisa deles para a sobrevivência ou o sucesso nos projetos que valoriza, mas sobretudo porque você anseia por obter sua estima (2000, p. 255).

A busca pela boa estima torna o indivíduo escravo da opinião pública e dependente de reconhecimento do outro para posicionar-se no sistema de honra hierárquica ${ }^{6}$, podemos perceber esta relação na estima de Mr. Darcy, personagem principal da literatura e que compõe o par romântico com Elisabeth:

Mr. Bingley não sabe a história toda, nem conhece as circunstâncias que Mr. Darcy achou ofensivas; mas ele garante a boa conduta, a probidade e a honra do seu amigo Mr. Darcy. Ele está inteiramente convencido de que Mr. Wickham não é de modo algum um rapaz respeitável. Creio que ele foi muito imprudente e mereceu perder a estima de Mr. Darcy (Austen, 1982, p. 92).

A construção da identidade é produto do relacionamento com o outro. Nesse sentido, Charles Taylor (2000, p. 245) apresenta o caráter dialógico que define a relação humana a partir da noção de que ninguém se define em sua interioridade ${ }^{7}$. O relacionamento com o outro, completa-se ao relacionamento consigo mesmo na formação do caráter identitário. Cada indivíduo possui sua própria medida, um modo peculiar de "ser no mundo" e de seus sentimentos para com o outro (Herder, 1877, p. 168), o que acarreta em uma identidade autêntica ${ }^{8}$, dada suas paixões e definições próprias de moral, sendo estas digna de respeito.

\footnotetext{
${ }^{5}$ Men should exhibit manliness and women shame, but the failure of either implies dishonor for the individual, the family and, in some cases, the entire community. For all, the qualities enjoined by honor provide the link, not only between self and community, but between self and the idealized norms of the community (Berger, 1983, p. 174). A concepção de honra na relação conjugal também é estudada por John Kennedy Campbell, Honour, Family and Patronage.

${ }^{6}$ Ver, por exemplo, a passagem em "Considerations sur le gouvernement de Pologne", em que ele descreve o antigo festival público de que participava todo o povo, em O contrato social, São Paulo, Cultrix, 1999 e a passagem paralela em "Lettre à D'Alembert sur les spectacles", em $D$ u contrat social, pp. 224-225. O princípio crucial era que não deveria existir nenhuma divisão entre os atores e os espectadores, mas sim que todos fossem vistos por todos. "Mais quels seront enfin les objets de ces spectacles? Qu'y montrera-t-on? Rien, si 1'on veut... Donnez les spectateurs en spectacles; rendez-les acteurs euxmêmes; faites que chacun se voie et s'aime dans les autres, afin que tous en soient mieux unis."[Mas quais serão enfim os objetos desses espetáculos? O que se mostrará neles? Nada, se se quiser... que os espectadores se tornem eles mesmos um espetáculo; torne-os eles mesmos atores; faça que cada um se veja e se ame nos outros a fim de que todos fiquem aí mais bem unidos.

${ }^{7}$ A concepção de interioridade é lastreada na ideia do pensamento platônico de que o "eu" e suas paixões precisam ser controlados em prol da razão. Santo Agostinho interpreta a formulação de Platão pela ideia de existência de mundo interior e mundo exterior e a verdade estaria dentro do sujeito, Deus seria a verdade. O interior representa a alma e constitui o sujeito e dela virá o conhecimento. Na formulação de Agostinho se percebe a construção de um discurso que desqualifica a necessidade do "outro" para formação do conhecimento e da verdade, bastando apenas atitude reflexiva interior.

${ }^{8}$ A concepção de autenticidade do indivíduo é fundamentada por Lionel Triling em Sincerity and Autenticity, Nova York, 1969
} 
A verdade universal que inaugura $O \& P$ revela a formação identitária monológica, fruto de um conformismo exterior e de uma atitude instrumental que moldam as ações de Elizabeth. As relações conjugais e o matrimonio perfaziam ideais de moral que suprimiam a originalidade e autenticidade dos indivíduos cuja vida era instrumentalizada pela tradição. A verdade universal, justamente por ser universal, não é verdade. As relações conjugais são importantes para constituição da identidade, mas a projeção de uma imagem inferior a modelos não convencionais infringe danos significativos, quando internalizados pelo indivíduo, e que por sua vez, devido a estrutura machista e falocêntrica acarreta danos considerados em um nível de maior opressão quando se trata de uma figura feminina, pois segundo Do Rosário e Oliveira (2017, p. 26): "Era através do enlace matrimonial que a mulher poderia ser, de qualquer modo, considerada verdadeira integrante "da sociedade". O homem, pois, era indispensável à constituição do sujeito feminino, ainda que fosse um "traste".

Os ensinamentos de Hegel trazem que: "É o modo mais habitual de enganar-se e de enganar os outros: pressupor no conhecimento algo como já conhecido e deixá-lo tal como está" (1992, p. 37). É na ideia de identidade autêntica, gestada na desconstrução da ideia de honra, que a modernidade fundamenta a concepção de dignidade humana ${ }^{9}$. A ideia de honra relaciona a formação do caráter identitário com um regramento social e moral instituído, enquanto o conceito moderno de dignidade aduz que a identidade se constrói independente de regramentos sociais. No princípio da dignidade, o indivíduo só pode descobrir a essência de sua identidade ao emancipar-se dos papéis socialmente impostos (Berger, 1983, p. 154). Hegel, ao publicar a Fenomenologia do Espírito em 1808, cinco anos antes da primeira edição de $O \& P$, aduz um pensamento de reconhecimento gestado pelo caráter dialógico e autêntico enquanto dignidade dos indivíduos.

\section{Do reconhecimento errôneo ao regime de comunhão recíproca entre iguais:}

"A felicidade no casamento é apenas uma questão de sorte" (Austen, 1982, p. 26). ${ }^{10}$

\footnotetext{
${ }^{9}$ A concepção de que o homem é portador de uma dignidade pode ser encontrada na Bíblia hebraica (na passagem do encontro de Natã com Davi); em Sofocles e a dramaturgia do encontro entre Antígona e Creonte. O que é peculiarmente moderno é a maneira como a concepção de dignidade está intrisicamente relacionado com a realidade social, a exemplo do artigo $1^{\circ}$ da Declaração Universal dos Direitos Humanos que reconhece seres humanos nascem livres e iguais em dignidade e em direitos (Berger, 1983, p. 176).

10 - Bem - disse Charlotte — desejo a Jane, de todo o coração, o mais completo êxito; e creio que se ela se casasse com ele amanhã, teria tanta probabilidade de ser feliz como se passasse um ano a estudar-lhe o caráter. A felicidade no casamento é apenas uma questão de sorte. Mesmo que os noivos conheçam mutuamente as suas tendências, mesmo que essas tendências sejam semelhantes, isto em nada contribui para a sua felicidade posterior. As diferenças, que se acentuam com o tempo, são sempre suficientes para que se venha a sofrer o seu quinhão de amargura; é melhor conhecer o menos possível os defeitos da pessoa com a qual temos de passar a vida (Austen, 1982, p. 26).
} 
Elizabeth, protagonista do romance, rejeita a lógica dos casamentos ao negar seus pretendentes que, antes de tentar conquista-la, a negociavam com sua família. Mr. Darcy, tido como um bom partido, desprezava os rituais matrimoniais (bailes, dotes, etc.) e detinha uma sensibilidade masculina diferente. Embora pertencessem a diferentes classes sociais, Elizabeth e Mr. Darcy sentem uma forte atração mútua. Todavia o casamento entre eles era indesejado e obstaculizado por sua família, desinteressada na baixa estima em que o matrimônio proporcionaria. As condutas de Elizabeth e Mr. Darcy são exemplos de atitudes autênticas ao protegerem suas convicções individualizadas de moral contra a imposição dos dogmas sociais, esse caráter formará o orgulho próprio. A autenticidade pujante dos protagonistas formará o preconceito deles ao afastar o caráter dialogal.

Quando Mr. Darcy propõe Elizabeth em casamento ela declara o desprezo que sente pela tradição imposta. Elizabeth, contaminada pela sua autenticidade, cega-se em reconhecer a identidade de Mr. Darcy e recusa o pedido, ao humilha-lo por entender ser um produto genérico de sua época. Nessa autenticidade aflorada que se encontra o preconceito capaz de inferiorizar o outro. Elizabeth apresentava-se a Mr. Darcy como uma mulher jovem, autêntica, intelectual e original, mas recebia dele a mensagem de ser uma mulher tola e inocente. Mr. Darcy apresenta-se pela sua racionalidade e blasé pela sociedade estereotipada e é compreendido por Elizabeth como um homem arrogante, pretensioso e indiferente com os sentimentos dos outros.

\footnotetext{
- Posso dizer que desde o princípio, desde o primeiro instante quase em que o conheci, as suas maneiras me convenceram de que era um homem arrogante, pretensioso, e de que tinha a maior indiferença pelos sentimentos dos outros. Esta impressão foi tão profunda que constituiu, por assim dizer, o alicerce sobre o qual os acontecimentos subsequentes elevaram uma indestrutível antipatia; e talvez menos de um mês depois de conhecê-lo estava convencida de que o senhor seria o último homem no mundo com o qual eu me casaria (Austen, 1982, p. 174).
}

Dado uma série de encontros e desencontros acidentais, a essência identitária de cada um é desvelada ao outro e então decidem se declarar em matrimônio. O duplo fracasso do primeiro encontro está interconectado pois Elizabeth encontra no orgulho de Mr. Darcy, a imagem inversa de seus próprios preconceitos; e Mr. Darcy encontra na vaidade de Elizabeth, a imagem inversa de seu próprio orgulho. Na deficiência percebida do outro, cada um percebe, ainda que sem saber, o preconceito de sua própria posição subjetiva. A falta do caráter dialogal, obstaculizada pela autenticidade excessiva, impediu a formação identitária e inferiu defeitos ao outro, desta forma na primeira experiência, ambos protagonistas atribuem uma concepção errônia do outro. Do Rosário e Oliveira (2017, p. 26) assinalam que: 
[...] a constituição do sujeito se dá na interação com o outro, quando o sujeito se completa. Esse sujeito, interpelado pela ideologia como tal, permanece numa articulação dialógica, constituído pelo outro e constituinte do outro. Para [Mikhail] Bakhtin, os sujeitos habitam e são habitados por diferentes vozes. A interação verbal é o espaço de constituição da linguagem, permitindo que, ao dialogarmos uns com os outros, participemos do processo de constituição de sujeitos. O outro do sujeito é um "nós".

Dado o pensamento de que o caráter dialógico define a relações humanas, refuta-se a concepção de Santo Agostinho de que a verdade é encontrada na interioridade do indivíduo, "não se pode ser um self por si só. Só sou um self em relação a certos interlocutores" (Taylor, 2005, p. 55) por meio de redes de interlocução. A identidade é formada tanto pela posição individual moral e espiritual, quanto por referências a comunidades em que se formou.

A cultura moderna desenvolveu concepções de individualismo que retratam a pessoa humana como, ao menos potencialmente, um ser que encontra suas coordenadas dentro de si mesmo, que declara independências das redes de interlocução que o formaram originalmente ou, ao menos, as neutraliza (Taylor, 2005, p. 56).

O casal, protagonistas de $O \& P$, é acometido por esta mazela da modernidade. O isolamento ontológico ilude a compreensão de si e dos outros. A heurística do self prescinde de ato de reconhecimento pelo pensamento linguístico reflexivo. A formação do sujeito moral se constitui ao relacionar-se com o outro, em direção ao outro, para o outro, mas também para si mesmo nas diversas arenas de interação (mundo da produção, mundo econômico, mundo cultural, relações mercantis, familiares, ...) (Gallardo, 2014, p.34). Esse círculo de troca, de reflexões e possibilidade de significações e ressignificações de sentimentos forma a identidade.

A possibilidade da fala e do discurso da identidade feminina na contemporaneidade ainda é muito articulada por premissas de sociedades falocêntricas, emitidas tanto por homens quanto por mulheres que reproduzem o pensamento dentro desta estrutura. A formação do self feminino, tanto em sua interioridade quanto nas redes de interlocuções, é maculada por ideologias misóginas e cenários políticos e culturais machistas. Para podermos compreender essa afirmativa, será disposta separadamente a formação dual do self feminino:

\section{a. Indentidade individualizada - a relação consigo mesma}

A formação da identidade individualizada, do ideal de autenticidade e orignalidade que compõe a moral do indivíduo, parte da concepção de que todo ser é "dotado das capacidades de razão, de consciência e de ação" (Hall, 2006, p. 10). A capacidade de razão e de consciência induz a pensarmos que cada indivíduo possui liberdade na formação de sua moral, por tratar-se de uma relação consigo mesmo. Tem-se desta forma a pureza da relação reflexiva privada ou individualizada, todavia, trata-se de uma teoria idealista. 
O pano de fundo que explicava o que as pessoas reconheciam como importante para si mesmas era em larga medida determinado por seu lugar na sociedade e pelos papéis ou atividades vinculadas com essa posição. O nascimento de uma sociedade democrática não acaba por sua simples existência com esse fenômeno, visto que as pessoas ainda podem se definir por seus papéis sociais (Taylor, 2000, p. 230).

O consciente subjetivo é mediatizado por fontes externas, desde o começo da formação fisiológica. A autenticidade é uma construção dialógica entre o indivíduo e as diversas forças sociais ao seu redor. A influência que sofremos de entes queridos, familiares ou amigos, é inevitável, mesmo após o desligamento material, como a morte. A consciência do que foi experimentado continuará a mediar a definição da moral individual e a formação do imanente por toda a vida. O desafio é esforçar-se para definir a autenticidade com maior autonomia possível e impedir a formação de qualquer dependência moral a outro indivíduo ou grupo (Taylor, 2005, p. 232).

As disparidades igualitárias de gênero podem ser espelhadas em políticas sociais, concepções de relações domésticas e trabalhistas e em produções culturais e artísticas ${ }^{11}$. A forte pressão das ideologias machistas infringe dano à formação individualizada da moral feminina, gerando o esforço para que se emancipem das tradições e construam uma identidade autêntica, o que torna intensamente mais complexo o processo da construção de uma identidade individualizada, já que para tal feito necessitam se desvencilhar da estrutura machista em que são criadas.

\section{b. Caráter dialógico - a relação com o outro}

Dado a inevitável necessidade de convivência com o outro, a linguagem é fundamental para o caráter dialógico. Heder e Humboldt foram dois expoentes da teoria da linguagem, seus estudos fundamentam a diferença entre os sistemas e sinais utilizados pelos animais da linguagem humana. Os signos linguísticos possuem uma carga de valor que é expressa pela articulação com vários signos. Enquanto para os animais os sinais emitidos pela fala são uma correlação de sua natureza com o mundo ao redor, a palavra emitida pelo ser humano apenas possui significado quanto dentro de um "jogo de palavras" pertencentes a um contexto específico (Wittgenstein, 1996, p. 58). Além do jogo de palavras, a linguagem também possui um "sentido amplo, cobrindo não só as palavras que falamos, mas também outros modos de expressão por meio dos quais nos definimos, incluindo as 'linguagens' da arte, do gesto, do amor etc" (Taylor, 2005 p.230).

${ }^{11}$ Há uma produção intelectual extensa que denuncia a desigualdade de gênero, dentre elas: (CAMPOS; TEIXEIRA, 2010). 
Ao prosseguirmos nesta pesquisa com a análise para além dos personagens e de sua relação enquanto indivíduo e com o outro, observamos que o contexto da obra literária transborda a linguagem. É razoável argumentar que a identidade feminina, através da literatura, se torna uma demanda social e jurídica que promove o questionamento de paradigmas sociais e políticos estabelecidos. Nessa toada, segundo Ribeiro:

\footnotetext{
Um texto literário contém alteridades, e, se o leitor conseguir captálas, será levado a deslocamentos desconstrutivos a partir de uma tomada de consciência de suas opiniões prévias, visões de mundo e preconceitos pessoais. Aí se encontra um prenúncio dos caminhos, possíveis, mas nunca pavimentados, que conduzem ao "por vir". (2019, p. 17)
}

A complexidade da dimensão linguística humana requer cuidado com o caráter dialógico para não inferir em reconhecimento errôneo. A linguagem possui irredutibilidade de justeza, encontrar uma palavra ou articulações que exprimam o real conceito que se pretende emitir é uma tarefa impossível, razão pela qual, o cuidado com a linguagem é extremamente importante (Taylor, 2005, p. 88). Quanto ao âmbito feminino, os descuidos com a alteridade de tratamento entre homens e mulheres é uma marca que assola a modernidade. Termos empregados por normas jurídicas, músicas, gírias e ditados populares colaboram para a formação de um reconhecimento errôneo de gênero e infringem sérios danos à dignidade pelo caráter de inferioridade que representam.

A exemplo de descuido como processo linguístico, Orestano (1997, p. 417) define como prejuízo ontológico o ato de descontextualizar e naturalizar direitos humanos e criar a falsa ideia de ser possível pensa-lo como universal, independente do contexto e dos sujeitos envolvidos. Adotar esta atitude reduz o valor das conquistas históricas sociais obtidas pelos movimentos feministas e os relaciona a um movimento racional interiorizado, onde apenas pela razão individual poderia chegar a fundamentar os direitos humanos das mulheres.

Mas como a política do reconhecimento se relaciona com o matrimonio? Como a construção identitária dialógica influi na felicidade do casamento? Voltemos a Austen! $O \& P$ representa a concepção de relações conjugais fundadas no ideal do amor romântico, muito difundido no século XVIII, mas já refletido séculos antes. O matrimônio torna-se fonte de felicidade por ser concebido em declarações amorosas e sexualidade consentida, uma fonte inesgotável de prazer que faz jus a metáfora do céu na terra. $\mathrm{O}$ amor um pelo outro é pensado como uma essência do indivíduo que precedesse sua própria existência e, assim, "um teria nascido para o outro" ou "'feitos um para o outro". Um amor tão forte que bastaria o primeiro 
encontro para ser aflorado, como Shakespeare narra em Romeu e Julieta. Uma análise complexa feita pela literatura. Nesse sentido, Ribeiro (2019, p. 17) argumenta que:

O processo de leitura é algo complexo e intrincado, e seus resultados são concretamente verificáveis. Desde o esforço inicial para a identificação com as personagens e os seus pontos de vista, passando pela construção mental das imagens que formam esse mundo de palavras e a quebra de estereótipos sobre o bem e o mal, o belo e o feio que vêm inseridos nas grandes narrativas, tudo isso concorre para que nossa percepção de mundo deixe de ser guiada por vetores de sentido menos centralizadores. E esse aprendizado não se dá por meio de conceitos ou de ideias abstratas, mas pela percepção da concretude e particularidade propiciada pela experiência da leitura.

Desta forma, a análise do matrimônio transcende do encontro romântico entre pessoas por uma identidade comum para a crítica da instituição do casamento celebrado por interesses mercantis. O movimento de promoção da igualdade de gênero mostra que, mesmo após diversas conquistas, ainda há um abismo enorme em termos de reconhecimento de igualdade entre os gêneros e de dignidade da mulher. Pesquisas apontam $^{12}$ que se mantem no século XXI a hegemonia da ideia da mulher vinculada a atividades domésticas e dependentes do homem enquanto provedor de sua subsistência material e social (Inglehart; Norris, 2005, p.22). Quando estamos diante de mulheres negras o abismo é ainda maior. Uma recente pesquisa realizada sobre a participação de mulheres no exercício da magistratura do Tribunal de São Paulo entre os anos de 1997 e 2017 apontou que "apesar da população negra corresponder a 32\% da população de São Paulo, na magistratura paulista há 20 juízas negras dentre os 2.547 juízes. No âmbito do Tribunal, 4 são desembargadoras negras em um quadro de 471 desembargadoras e desembargadores incluso os substitutos" (Lima; Lulia, 2020, p. 17)

A relação conjugal é um constructo dialógico como qualquer relação social, sendo importante para definição de identidade ${ }^{13}$. Negado o caráter dialógico e moldado por uma racionalidade individualizada, o amor traduz-se em preconceito e molda uma distorção da identidade. Em consequência, segundo dados do IBGE, o número de separações tem aumentado muito nos últimos anos enquanto o número de casamento tende a decrescer. Nesse sentido, sendo exceção à política do reconhecimento nas relações conjugais, a felicidade no casamento ainda é uma questão de sorte. Podemos suspeitar que a violência passional seja uma

\footnotetext{
${ }^{12}$ Segundo Jablonski: A par das diferenças culturais e dos avanços a reboque do movimento feminista, parece persistir uma visão conservadora dos papéis dos cônjuges no que se refere às tarefas domésticas e à responsabilidade pelo cuidado e educação dos filhos. Teoricamente, as perspectivas dos recursos econômicos relativos e de gênero têm predominado na base da literatura a respeito. A primeira enfatiza os aspectos racionais/econômicos e leva em conta os ganhos relativos de homens e mulheres na alocação de tarefas domésticas. Essa perspectiva pressupõe maior igualdade em função dos crescentes e substanciais ganhos femininos em termos de educação e salários, entre outros. (2003, p. 3).

${ }^{13}$ Nesse sentido, Taylor (2005, p. 232): "As relações amorosas não são importantes apenas por causa da ênfase geral da cultura moderna no atendimento de necessidades comuns". No mesmo sentido Michel de Montaigne (1980, p. 68) questionado sobre amor de amizade que nutria com Étienne de La Boétie, neste caso não se tratava de uma relação conjugal, disse: "Se insistirem para que eu diga por que o amava, sinto que o não saberia expressar senão respondendo: porque era ele; porque era eu".
} 
consequência da construção monológica de amor, ou que ao menos a política de reconhecimento autêntico possa evitar essas condutas.

No âmbito dessas perspectivas, o reconhecimento errôneo não se limita a faltar ao devido respeito, podendo ainda infligir uma terrível ferida, aprisionando suas vítimas num paralisador ódio por si mesmas. O devido reconhecimento não é uma mera cortesia que devemos conceder às pessoas. É uma necessidade humana vital" (Taylor, 2005, p. 242).

Por depender de um esforço cotidiano de respeito à autenticidade do outro e de dedicação a um agir dialogal e equânime, não podemos dizer o amor floriu na primeira troca de olhares, o sentimento desta ocasião é apenas a reação de hormônios liberados na corrente sanguínea com sinais elétricos recebidos no cérebro. Seria falta de consideração aos casais que nutrem anos, décadas, de respeito e admiração mútua, assim como a crítica de Orestano do prejuízo ontológico ao tornar essencial os direitos humanos, desconsiderando todo o processo histórico social de sua conquista.

Podemos pensar que, se Elizabeth e Mr. Darcy tivessem levado o matrimonio adiante já no primeiro encontro, talvez nunca conhecessem a identidade autêntica um do outro e de si mesmo. Para buscar felicidade nas relações conjugais é importante o reconhecimento como diferente, mas igual em dignidade. A felicidade do casal importa no reconhecimento recíproco de dignidades iguais, um regime de comunhão recíproca de identidades. De modo que não se deve buscar a felicidade no casamento, mas buscar o casamento na felicidade.

\section{Crítica a uma cultura estática e anestesiada da igualdade de gênero:}

"Que importam os homens aos rochedos e às montanhas?"(Austen, 1982, p. $141-142^{14}$

Há um abismo existente entre teoria e prática quando se fala em igualdade de gênero. As comunidades científicas e políticas compreendem a importância dos direitos humanos como legitimadores de justiça em democracias. Todavia, adequar ao dia-a-dia os preceitos teóricos é uma tarefa difícil. Este plano duplo é denominado como bipolaridade separadora por Rúbio (2015, p. 101).

\footnotetext{
${ }^{14}$ - Minha querida tia! - exclamou ela, deliciada. - Que encanto, que felicidade! A senhora me inspira nova vida e vigor. Adeus desapontamentos e tristezas. Que importam os homens aos rochedos e às montanhas? Oh, quantas horas agradáveis vamos passar! E quando voltarmos, não faremos como os outros viajantes que nada podem descrever com precisão. Nós nos lembraremos dos lugares que visitamos e das coisas que vimos. Lagos, montanhas e rios não se confundirão nas nossas lembranças. Nem quando tentarmos descrever uma cena, discutiremos a respeito da sua localização. E que as nossas primeiras efusões sejam menos insuportáveis do que as da maioria dos viajantes! (AUSTEN, 1982, p. 141-142)
} 
Esta distancia entre la teoria y la prática que damos como natural e indicutible es uma de las razones que justifican la indolência y la pasividad a la hora de construir (o destruir) día a día y em todos los lugares sociales, derechos humanos. (Rúbio, 2015, p. 103)

O mesmo cenário ocorre nas políticas de igualdade de gênero. Durante o final do século XX, a temática da igualdade de gênero, tomou a agenda global. A Década da Mulher pelas Nações Unidas (1975-1985) iniciou a integração das mulheres na geopolítica internacional e a formação de organizações de mulheres em todo o mundo. Em 1993, a II Conferência Internacional de Direitos Humanos em Viena proclamou como direitos humanos os direitos das mulheres; em 1994, a Conferência Internacional sobre População e Desenvolvimento no Cairo imprimiu a capacitação e saúde da mulher em programas de desenvolvimento sustentável. Dois anos mais tarde, a IV Conferência Mundial sobre as Mulheres em Beijing adotou uma plataforma de promoção e proteção do pleno gozo dos direitos humanos e liberdades fundamentais para todas as mulheres. Mesmo diante do progresso normativo das últimas décadas, grandes disparidades persistem.

Mais e mais mulheres entram na força de trabalho assalariada, formando a transição do homem provedor para famílias de duplo rendimentos ou de mulheres provedoras. Embora a diferença de gênero nas taxas de participação econômicas vem se tornando melhores, os papéis das mulheres e dos homens na força de trabalho continuam a divergir. As mulheres têm de equilibrar as demandas de responsabilidades familiares ao mercado de trabalho além de possuírem diferentes postos de trabalho, muitas vezes com status e salários inferiores. Estas tendências sociais levantam questões sobre valores morais estabelecidos há muito tempo e atitudes com os papéis familiares e de gênero. Valores familiares tradicionais também não desapareceram, mas estão sob maior pressão na contemporaneidade. Percebemos que as críticas formuladas por Austen, mesmo que em uma época distante, reflete ainda hoje em demandas de defesa da igualdade de gênero e da emancipação feminina no cenário social.

A entrada das mulheres casadas no mercado de trabalho, que expande os rendimentos familiares, pode revelar-se mais socialmente aceitável para homens do que a igualdade na divisão das tarefas domésticas comuns, como cuidados de casa e cuidado de crianças e de idosos. No Brasil, os dados do IBGE nos apontam que as mulheres gastam 25,2 horas semanais com trabalhos domésticos e os homens, 9,8 horas (Soares; Sabóia, 2007, p. 25). Não apenas as estatísticas mostram que mulheres possuem salários menores que os homens como também em competições esportivas possuem premiações financeiras menores para modalidades femininas. 
Mulheres que trabalham em setores como a educação, saúde e organizações voluntárias, refletem papéis sexuais tradicionais de mulheres como cuidadoras, em oposição a barreiras que esses estereótipos sexuais possuem em carreiras militares ou políticas. Os homens continuam a manter os costumes de uma sociedade misógena, ainda não fazem parte do trabalho familiar de forma igualitária, sendo este ofício considerado "trabalho de mulher", mesmo quando mulheres também são assalariadas ou até mesmo provedoras da família. O reconhecimento das mulheres ainda é obstaculizado pela depreciação do feminino nas sociedades patriarcais:

[...] as mulheres eram induzidas a adoptar uma opinião depreciativa delas próprias. Interiorizavam uma imagem da sua inferioridade, de tal maneira que, quando determinados obstáculos reais à sua prosperidade desapareciam, elas chegavam a demonstrar uma incapacidade de aproveitarem as novas oportunidades. E, além disso, estavam condenadas a sofrer pela sua debilitada auto-estima (Taylor, 1994, p. 46).

Políticas de igualdade e de oportunidades que refletem as crenças liberais clássicas revelam-se mais populares do que estratégias destinadas a alcançar ações afirmativas, paridade de gênero, ou discriminação positiva para mulheres. Nas democracias liberais, a reforma da legislação discriminatória é considerada como o principal modo de transformar exclusão em inclusão.

A violência perpetrada por homens contra suas parceiras é um fenômeno presente em todos os países do mundo. A Organização Mundial da Saúde estima que mais de um terço das mulheres no mundo têm sido vítimas de diversos tipos de violência física ou sexual. É uma violação fundamental dos direitos humanos das mulheres e um problema de saúde pública, com custos econômicos e sociais significativos. No Brasil, os dados sobre violência doméstica contra mulher são expressivos ${ }^{15}$ e justificam o senso de importância e urgência de políticas sociais.

Conflitos domésticos atrelados a inserção da mulher no mercado de trabalho e sobre a violência contra mulher refletem o aumento de separações no Brasil. Dados do IBGE (2014, p. 51) apontam grande crescimento estatístico de divórcios no Brasil e leve crescimento de novos casamentos (2014, p. 40), com intervalos de decréscimos em alguns anos, nas últimas três décadas. O imaginário romântico fomentado no século XVIII e imposto no imaginário feminino até então e, de certo modo, no masculino também, entra em colapso com uma relação individualizada que a sociedade contemporânea instiga.

\footnotetext{
${ }^{15}$ Para obter dados estatísticos sobre violência contra mulher no Brasil recomendamos a leitura de: Magalhães, Andreia Brito et al. Violência contra à mulher registrada no brasil entre os anos de 2006 a 2011. Revista Ciência \& Polícia, v. 1, n. 3, p. 88-108, 2015.
} 
No Brasil o Judiciário tornou-se o poder de supervisão mais importante sobre as políticas sociais do Estado. Mais recentemente, a política nacional presenciou o desmantelamento do Ministério das Mulheres, fechado em 2016. O Brasil possui uma legislação que, há pouco tempo, possuía previsões de termos como "mulher honesta" e "legítima defesa da honra" para casos de traição em que o marido atentasse contra a vida de sua mulher e do amante. Esses exemplos do âmbito nacional vão de encontro a política de reconhecimento de igualdade de gêneros. A política de reconhecimento de Charles Taylor ${ }^{16}$, aponta razões normativas capazes de engendrar uma conjuntura social desequilibrada. As estruturas familiares do século XXI repetem o desequilíbrio de tempos remotos e ilustrados por Austen.

O prejuízo ontológico nos induz a pensar que qualquer modelo de afetividade que não detenha os dogmas matrimonias tradicionais seja uma modelo inferior, aspecto apontado por Austen quando sua personagem Elisabeth se vê em insegurança de decidir entre aceitar casarse, honrando sua família e se adequando ao dogma imposto sobre o casamento pela sociedade, ou seguir seus preceitos morais independente da crítica de sua época. Em nossa atual realidade vemos nesse sentido, propostas legislativas ${ }^{17}$ que pretendem cristalizar o modelo familiar como apenas a união entre homem e mulher a partir de uma racionalidade individualizada e não dialogada. A tentativa de naturalização de família é característica de um "reconhecimento errôneo" ou "reconhecimento inautêntico" e fruto de uma atuação racional individualizada e descontextualizada. A moral que rege essas condutas são produtos de tradições inautênticas, há uma naturalização das relações sociais e pouco se dialoga sobre elas (Taylor, 2005, p. 274). Ao mesmo tempo em que propostas conservadoras de uma tradição inautêntica são formuladas, a criminalização de movimentos sociais é fomentada.

No es de extrañar que hoy en día se criminalice a aquellos movimientos sociales que luchan o bien por el cumplimiento de derechos jurídicamente reconocidos, o bien por la legitimidad de nuevos derechos no objetivados en las normas constitucionales. Resulta ser un contrasentido que el elemento que da origen y fundamento a los mismos, la lucha social, sea denigrada, descalificada y demonizada por los medios de comunicación y por las instancias gubernativas y estatales. Esto es lo que sucede, por ejemplo, en España y en Brasil con las protestas ciudadanas a favor de los servicios públicos, por motivo de la crisis económica y las políticas privatizadoras, o por los mega proyectos de la minería o del mundial de fútbol de 2014, o, incluso, por las movilizaciones populares producidas en defensa y en favor del derecho a la vivienda frente a los desahucios o por los conflictos relacionados con la posesión y la titularidad de la tierra (MST, movimientos campesinos, pueblos indígenas y movimientos sin techo). (Rúbio, 2015, p. 117).

\footnotetext{
${ }^{16}$ Os estudos de Taylor foram reconhecidos pelo Prêmio Kluge, popularmente dito como Nobel das Humanas.

${ }^{17} \mathrm{O}$ projeto de lei $\mathrm{n}^{\circ} 470$, de 2013 dispõe de entidade familiar a união estável entre o homem e a mulher.
} 
Trata-se de um movimento de despolitização dos direitos humanos atrelado a compreensões técnicas oriundas de um poder instituído. Há uma tentativa de relacionar a afirmação de direitos apenas às instituições estatais e desvincular dos movimentos sociais o protagonismo nas lutas por direitos. É equivocado o pensamento de que os direitos humanos e/ou princípios e valores que os inspiram são definidos por sentenças judiciais ou construídas por teorias jus filosóficas. A essência dos direitos humanos parte do conjunto de relações que buscam a efetividade em cada contexto (Rúbio, 2015, p. 123). No mesmo sentido, a igualdade de gênero nas relações matrimoniais não será modelada por entidades instituintes, mas se dará pelas ações cotidianas, individuais ou coletivas.

A concepção de tradição está naturalizada na sociedade e dela refletem o cenário misógino e falocêntrico em que vivemos. O caráter dialógico do ser humano exige a relação e a ressignificação de valores pelo "outro" para contrabalancear uma tradição que se repete e que se naturaliza por retirar tal caráter, que por sua vez, é a principal caraterística humana. "A possibilidade de superação inovadora de tradições é garantida pela possibilidade sempre existente da articulação reflexiva de novos sentidos linguísticos e valorativos" (Souza, 2000, p. 140). Esta articulação reflexiva dos novos sentidos linguísticos e valorativos apontados por Souza, conta com a contribuição do papel do Direito vinculado à Literatura para repensar as tradições perpetuadas e espelhadas por instituto jurídico. Sujeitos dialogáveis constituem a premissa para reconhecimento autêntico em nossa sociedade que se diz moderna com muitas aberturas para fala e poucas para ouvir.

\section{Considerações finais}

"eu desejaria poder acrescentar, para bem da família, que a realização dos seus mais caros desejos tivera o feliz efeito de torná-la uma mulher sensata, discreta e interessante para o resto da sua vida" (Austen, 1982, p. 333)

A melhor maneira de entender a nós mesmos e a estes seres fictícios do século XVIII e XIX é considerar o quanto o mundo mudou. Nesse campo em que o Direito à Literatura, defendido por Antonio Candido (2017, p. 188), ganha força e importância: "A literatura corresponde a uma necessidade universal que deve ser satisfeita sob pena de mutilar a personalidade, porque pelo fato de dar forma aos sentimentos e à visão do mundo ela nos organiza, nos liberta do caos e portanto nos humaniza”. Nesse campo temos que fundamental 
importância de avançar nos estudos sobre igualdade, em suas diversas fases pontuadas na história das ideias jurídicas ${ }^{18}$.

Não apenas nos sinais exteriores como trajes e arquitetura, mas nas reivindicações de deveres, honra, status, família, dinheiro e amor. Apesar de reconhecer que alguns dos costumes da época de Austen não permanecem em nosso tempo moderno, o imaginário falocêntrico ainda envolve nossas relações sociais, os comportamentos éticos e morais da era georgiana no Reino Unido foram adaptados aos novos costumes de nossos tempos.

Austen ficciona a mentalidade da época de transição do casamento enquanto união jurídica entre famílias para concepção de união consenssual e amorosa entre pares. Esta transição simboliza a passagem da ética da da honra para a ética da dignidade enquanto princípios da sociedade. A verdade universal do século XVIII continua presente no século XXI, mas com uma nova roupagem. Conflitos domésticos e desigualdes de gênero nas relações conjugais continuam sendo um impecílio para formação da identidade feminina. A relação conjugal é um constructo dialógico como qualquer relação social e importante para definição de identidade. Negado o caráter dialógico e moldado por uma racionalidade individualizada, o amor traduzira-se em preconceito e moldará uma distorção da identidade.

A análise de $O \& P$ pela interdisciplinaridade entre a Literatura e o Direito promove um aprofundamento de reflexões sobre nossas instituições jurídicas. A forma romantizada em que Jane Austen trata o matrimônio retrata criticamente que o matrimônio se vincula a ascensão social e não reflete o sentimento de aceitar o "outro" sem que a ele seja imposto como uma obrigação. O matrimônio considerado como uma forma de se obter estima social e afronta a dignidade feminina e seu direito de manifestação de vontade na escolha querer estar ou não em comunhão matrimonial.

\section{Referências}

AUSTEN, Jane. Orgulho e preconceito. Tradução de Lúcio Cardoso (Grandes sucessos). São Paulo : Abril Cultural, 1982.

BERGER, Peter. On the Obsolescence of the Concept of Honour. Revisions: Changing Perspectives in Moral Philosophy, Notre Dama: Stanley Hauerwas e Alasdair Maclntyre, pp. 172-181, 1983.

BLACKSTONE, William. Commentaries on the laws of England. v. I. São Francisco: Bancroft-Whitney Company, 1915.

\footnotetext{
${ }^{18}$ Nesse sentido, a pesquisa de Aletya Dahana Rollwagen e Rosalice Fidalgo Pinheiro (2020, p. 176-180) apresenta de forma detalhada a evolução do fundamento da proibição de discriminação no Direito Privado.
} 
CANDIDO, Antonio. Radicais de ocasião. Discurso, n. 9, 2017.

CANDIDO, Antonio. Vários escritos. 6. ed. Rio de Janeiro: Ouro Sobre azul, 2017.

CAMPOS, Marta Silva; TEIXEIRA, Solange Maria. Gênero, família e proteção social: as desigualdades fomentadas pela política social. Revista Katálysis, v.13, n.1. Florianópolis, 2010 .

DO ROSÁRIO, Luana Paixão Dantas; OLIVEIRA, João Mateus Silva Fagundes. Aurélia Camargo: sujeito feminino de direito e de linguagem-o discurso jurídico em "Senhora", de José de Alencar. Anamorphosis: Revista Internacional de Direito e Literatura, v. 3, n. 2, p. 519-544, 2017.

GALLARDO, Helio. Teoria crítica: matriz e possibilidade de direitos humanos. São Paulo: Ed. Unesp, 2014

GILLIS, John R. For Better, For Worse: British Marriages, 1600 to the Present. New York: Oxford University Press, 1985. Disponível em:

http://books.google.com/books?id=t3kiLAQxrnMC\&lpg=PP1\&pg=PP1\#v=onepage\&q\&f=fal se. Acesso em: 25 jun. 2016.

HALL, Stuart. A identidade em questão. In: Hall, Stuart. A Identidade cultural na pósmodernidade. 11. ed. Rio de Janeiro: DP\&A, 2006.

HEGEL, Georg Wilhelm Friedrich. Fenomenologia do espírito. Petrópolis: Vozes. 1992

HERDER, Johann Gottfried. Gesammelte Werke. Berlim: Bernhard Suphan. 1877. Disponível em: http://www.anova.at/1sitemap/Philosophie/28-Herder,\%20J\%20G\%20\%20Gesammelte\%20Werke.pdf. Acesso em: 05 jul. 2016.

INGLEHART, Ronald; NORRIS, Pippa. Rising Tide: Gender Equality and Cultural Change around the World. Nova York: Cambridge University Press, 2005

INSTITUTO BRASILEIRO DE GEOGRAFIA E ESTATÍSTICA (IBGE). Síntese de indicadores sociais. Rio de Janeiro: IBGE, 2014.

JABLONSKI, Bernardo. A divisão de tarefas domésticas entre homens e mulheres no cotidiano do casamento. Psicologia: Ciência e profissão, v. 30, n. 2, p. 262-275, 2010.

LIMA, Renata Miranda; LULIA, Luciana Toledo Temer. Estudo sobre gênero e raça: mobilidade no Tribunal de Justiça do Estado de São Paulo. Prisma Jurídico, São Paulo, v. 19, n. 1, p. 2-22, jan./jun. 2020. http://doi.org/10.5585/prismaj.v19n1.14254.

MONTAIGNE, Michel de. Ensaios. Tradução de Sergio Milliet. São Paulo: Abril Cultural, 1980.

MONTESQUIEU. O espírito das leis. Tradução de Cristina Murachco. São Paulo: Martins Fontes, 2000. 
ORESTANO, Riccardo. Introducción al estúdio del derecho romano. Traducción de. Manuel Abellán Velasco. Madrid: Universidad Carlos III de Madrid, 1997.

ORTEGA Y GASSET, José. A Rebelião das Massas. São Paulo: Martins Fontes, 1987.

PEPE, Albano Marcos Bastos. Direito e Literatura: uma intersecção possível? Interlocuções com o pensamento waratiano. Anamorphosis - Revista Internacional de Direito e Literatura, v. 2, n. 1, p. 7, jul./dez. 2016.

RIBEIRO, Fernando Armando. "Essa estranha instituição chamada literatura" e o direito. ANAMORPHOSIS-Revista Internacional de Direito e Literatura, v. 5, n. 2, p. 465-489, 2019.

ROLLWAGEN, Aletya Dahana; PINHEIRO, Rosalice Fidalgo. Orlando. Proibição de discriminação da pessoa com deficiência: a incidência do princípio da igualdade nas relações privadas. Prisma Jurídico, São Paulo, v. 19, n. 1, p. 174-193, jan./jun. 2020. http://doi.org/10.5585/prismaj.v19n1.16764.

ROUSSEAU, Jean-Jacques. O Contrato Social. Tradução de Tiago Rodrigues da Gama. São Paulo: Russel, 2006.

RUBIO. David Sánchez. Crítica a una cultura estática y anestesiada de derchos humanos: por uma recuperación de las dimensiones constituyentes de la lucha por los derechos. Derechs y Libertades, n. 33, época II, jun. 2015

SOARES, Cristiane; SABÓIA, Ana L. Tempo, trabalho e afazeres domésticos: um estudo com base nos dados da Pesquisa Nacional por Amostra de Domicílios de 2001 e 2005. Rio de Janeiro: IBGE, Coordenação de população e indicadores sociais, 2007.

SOUZA, Jessé. Uma teoria crítica do reconhecimento. Lua Nova, São Paulo, n. 50, p. 133158, 2000 . Disponível em: http://dx.doi.org/10.1590/S0102-64452000000200008. Acesso em: 19 jul. 2016.

TAYLOR, Charles. A política de reconhecimento. In: TAYLOR, Charles et al.

Multiculturalismo: examinando a política de reconhecimento. Trad. Marta Machado. Lisboa: Piaget, 1994. p. 45-94.

TAYLOR, Charles. Argumentos filosóficos. Edições Loyola, 2000.

TAYLOR, Charles. As fontes do self: a construção da identidade moderna. Edições Loyola, 2005.

TRILLING, Lionel. Sincerity and authenticity. Harvard University Press, 2009.

TRINDADE, André Karam. Mais literatura e menos manual - a compreensão do Direito por meio da ficção. Revista do Instituto Humanitas Unisinos. Entrevista por Ricardo Machado. Disponível em:

http://www.ihuonline.unisinos.br/index.php?option=com_content\&view=article \&id $=5503 \&$ secao $=444$. Acesso em: 21 mar. de 2020. 
TRINDADE, André Karam; BERNSTS, Luísa Giuliani. O estudo do" direito e literatura" no Brasil: surgimento, evolução e expansão. ANAMORPHOSIS-Revista Internacional de Direito e Literatura, v. 3, n. 1, p. 225-257, 2017.

WARAT, Luis Alberto. A ciência jurídica e seus dois maridos: fragmentos de uma expedição pelo direito, pela ciência e outros lugares de arrogância. Faculdades Integradas de Santa Cruz do Sul, 1985.

WITTGENSTEIN, Ludwig. Investigações filosóficas. Tradução de Marcos G. Montagnoli. 2.ed. Petrópolis: Vozes, 1996.

ZIZEK, Slavoj. O mais sublime dos histéricos: Hegel com Lacan. Rio de Janeiro: Zahar, 1991. 